\title{
Radiation Therapy for Uterine Cervical Cancer With Lung Metastases Including Oligometastases
}

\author{
YUKI MUKAI $^{1 *}$, IZUMI KOIKE ${ }^{1}$, TATSUYA MATSUNAGA ${ }^{2}$, NAHO RUIZ YOKOTA ${ }^{2}$, \\ SYOKO TAKANO $^{1}$, MADOKA SUGIURA ${ }^{1}$, MIZUKI SATO ${ }^{1}$, ETSUKO MIYAGI $^{2}$ and MASAHARU HATA ${ }^{1}$ \\ ${ }^{1}$ Department of Radiation Oncology, Yokohama City University Graduate School of Medicine, Yokohama, Japan; \\ ${ }^{2}$ Department of Obstetrics and Gynecology, \\ Yokohama City University Graduate School of Medicine, Yokohama, Japan
}

\begin{abstract}
Background/Aim: To investigate the role and outcomes of radiation therapy (RT) for stage IVB uterine cervical cancer (UCC) patients with lung (oligo) metastases due to the lack of recent reports on the subject. Patients and Methods: The cohort for this retrospective study comprised 23 consecutive patients with UCC (squamous cell carcinoma, $n=13$ ) and lung metastases who had received pelvic $R T$. Ten had lung metastases only, including 7 with oligometastases ( $\leq 4$ lung metastases); the remaining 13 also had other distant metastases. Results: Nine (39.1\%) of the 22 patients (95.7\%) completed RT without interruption. The 1-year primary progression-free rate was $95.2 \%$. The 1-year overall survival rate was $47.2 \%$ (estimated median survival: 9 months). Significant prognostic factors for survival included: i) $\leq 4$ lung metastases $(p=0.035)$, ii) unilateral lung metastases $(p=0.039)$, iii) primary tumor diameter $<100 \mathrm{~mm}$ $(p<0.001)$, and iv) ECOG performance status $<1 \quad(p=0.015)$. Conclusion: RT is safe and effective for stage IVB UCC patients with lung metastases.
\end{abstract}

The incidence of uterine cervical cancer (UCC) has been declining in many countries due to widespread implementation of cytological screening. However, the incidence of cervical cancer remains at the same level in Japan and is not decreasing (1). It is currently widely accepted that radiation therapy (RT) has an important role in

This article is freely accessible online.

Correspondence to: Yuki Mukai, Department of Radiation Oncology, Yokohama City University, Graduate School of Medicine, 3-9 Fukuura, Kanazawa-ku, Yokohama, Kanagawa 2360004, Japan. Tel: +81 457872800, Fax: +81 457860369, e-mail: y_mukai@yokohama-cu.ac.jp

Key Words: Uterine cervical cancer, radiation therapy, lung metastases, oligometastases, gynecological malignancies. treating this disease, especially when at an advanced stage without distant metastasis.

Between $2.9 \%$ and $14 \%$ of patients with cervical cancer reportedly have Stage IVB disease at the time of diagnosis (2, 3 ). For many years, the treatment outcomes in patients with Stage IVB disease have been poor, excluding those with paraaortic lymph-node metastasis alone (4-6). Some studies have focused on a definitive radiation therapy for oligometastatic cervical cancer, including metachronous and synchronous metastases (7), and on differences between hematogenous and lymphatic metastasis (8). These studies have found that, depending on the site of metastasis, there is some potential to achieve longer survival in patients with Stage IVB disease or distant recurrence. Lung metastases are hematogenous metastases (8), the lung being the most common site of hematogenous metastasis, followed by liver and bone (9).

Several previous studies analyzing the treatment of lung metastases from cervical cancer have included both metachronous (lung metastasis following initial therapy) and synchronous (Stage IVB at the time of initial diagnosis) disease; in most of these studies a few of the patients had Stage IVB disease (10). To the best of our knowledge, no studies have previously investigated the prognostic factors in UCC with synchronous lung metastases (Stage IVB) in detail. We, thus, investigated the role and outcomes of radiation therapy (RT) in patients with synchronous lung (oligo) metastases from UCC.

\section{Patients and Methods}

Patients. Between November 2005 and July 2017, 23 patients with lung metastases from UCC received RT to the pelvis at our institution at initial diagnosis. Their medical records were reviewed in this retrospective study. All patients had been treated with a curative or palliative intent and were eligible for this study.

The clinical stage was determined by findings from: i) physical examination, ii) basic laboratory studies, iii) chest $\mathrm{X}$-ray, iv) contrast-enhanced computed tomography (CT) of the neck to the pelvis, and v) magnetic resonance imaging (MRI) of the pelvis. 
Some patients went under whole-body positron emission tomography-computed tomography (PET-CT). Bladder and rectum status were determined by cystoscopy and colonoscopy, if necessary, respectively. All patients were examined before treatment by gynecologists and radiation oncologists and their disease was classified according to the Union for International Cancer Control (UICC) staging system (11). Their disease characteristics are summarized in Table I.

All patients had lung metastases; 10 had only lung metastases, whereas the remaining 13 had additional distant metastases to other sites, including para-aortic lymph nodes, liver, bones, peritoneum, and ovaries.

Seven patients had $\leq 4$ lung metastases, which were considered oligometastases. This study was approved by our Institutional Review Board (IRB number, B190100015) and informed consent was obtained from all patients prior to treatment.

Radiation therapy. All 23 patients received RT with threedimensional radiation therapy (3DCRT) to the whole pelvic radiation field using two to four beams. Box field (four beams) was used in 21 patients and anterior-posterior fields (two beams) using $15 \mathrm{MV} \mathrm{X}$-rays were delivered in the remaining two patients.

The gross tumor volume (GTV) was defined as the primary tumor and involved lymph nodes and the clinical target volume (CTV) as the primary tumor plus a $5 \mathrm{~mm}$ margin; this included the pelvic lymph nodes and the parametrium. The CTV for lymph nodes included the common, external and internal iliac, and obturator nodal regions and extended to the level of the L4-5 interspace. The caudal edge of the radiation field was defined according to the extent of primary disease invasion. (for example, the lower edge of foramen fossa/ sciatic foramen or entire vagina).

The planning target volume (PTV) was delineated with a 10-15 $\mathrm{mm}$ margin around the CTV. Normal structures, including bladder, rectum, small bowel, and femoral heads, were contoured as organs at risk (OARs) in the radiation field. Four patients had inguinal node metastases and one had ischial bone metastasis, all of which were included in the radiation field.

All study patients received external irradiation, the median prescribed total dose to the pelvis being 50.4 Gy (range=27-50.4 $\mathrm{Gy}$ ). Fraction size was 1.8-2.5 Gy and fractions were delivered on 5 consecutive days per week, using $15 \mathrm{MV}$ X-rays. Fifteen patients $(65.3 \%)$ received high-dose-rate intracavitary brachytherapy (HDR-ICBT). The remaining patients did not receive HDR-ICBT because their cervical tumors did not shrink enough to warrant intracavitary application. HDR-ICBT was performed using Ir-192 using microSelectron-HDR (Nucletron, the Netherlands). The standard regimen of HDR-ICBT in our institution is 5 Gy per fraction for point A. Point A was located at $2 \mathrm{~cm}$ lateral and $2 \mathrm{~cm}$ vertically above from uterine cervical. The median dose of HDR-ICBT was $15 \mathrm{~Gy}$ in three fractions (range=5$26 \mathrm{~Gy}$, in one to five fractions). Four patients with pelvic lymph node involvement received an additional boost to those lesions following whole-pelvic radiation therapy (WPRT), up to 55.4-56.4 Gy. Only one patient had an additional boost irradiation for her primary tumor, up to $56 \mathrm{~Gy}$.

The median duration of all treatments, including EBRT and HDR-ICBT, was 43 days (range=19-63 days). Twenty-two $(95.7 \%)$ patients completed the planned RT for their primary tumors. Only one patient discontinued the treatment due to deterioration of their general condition.
The biological effective dose (BED) to the rectum was calculated from a linear quadratic model using $\alpha / \beta$ ratios of 3 for a late effect and $\alpha / \beta$ ratios of 10 for an early effect. The total equivalent dose in 2 Gy fractions (EQD2) to the primary tumor $(\alpha / \beta=10)$ was also calculated.

The median BED $(\alpha / \beta=3)$ to the rectum was 103.4 (range $=43.2$ 122.9) Gy and the $\operatorname{BED}(\alpha / \beta=10)$ to the rectum 70.4 (range=31.982.0) Gy. The median EQD2 $(\alpha / \beta=10)$ to the primary tumor was 62.1 (range=26.6-68.3) Gy. In one patient who was under palliative treatment, the EQD2 was 36.5 Gy and another patient discontinued RT after receiving an EQD2 of $26.5 \mathrm{~Gy}$. After excluding these two patients, the median EQD2 was 62.1 (range=44.3-68.3) Gy.

Fourteen of the 23 patients had chemotherapy concomitant with RT consisting of weekly cisplatin $\left(40 \mathrm{mg} / \mathrm{m}^{2}\right.$ of the body surface area) for a median of four courses (range $=2-6$ ). Two patients received two courses of a combination of paclitaxel and carboplatin. The reasons for the remaining seven patients not receiving chemotherapy were as follows: i) poor performance status (PS) $(n=3)$, ii) renal dysfunction $(n=3)$, and iii) carrier of hepatitis B virus $(n=1)$.

Evaluation criteria and statistical analysis. Responses were evaluated by clinical examination and CT from the neck to the pelvis within approximately 4-6 weeks following the completion of the treatment. Tumor responses were assessed using the Response Evaluation Criteria in Solid Tumors (RECIST v1.1) (12).

Toxicities associated with treatments were evaluated using the Common Terminology Criteria for Adverse Events v4.0 (13). Acute toxicities were defined as therapy-related adverse events that occurred within 3 months following the beginning of treatment and late toxicities as those occurring after 3 months.

The overall survival (OS) and local control (LC) rates from the beginning of each treatment were calculated using the Kaplan-Meier curves. Differences between curves were tested by the log-rank test using the Statistical Package for the Social Sciences (SPSS for Windows, version 23.0; IBM, Armonk, NY, USA). A $p$-Value $<0.05$ was considered to denote significance.

\section{Results}

Local control rate. The median follow-up time was 9 (range=1-78) months. Figure 1 shows Kaplan-Meier curves for the local control rate (LC). The overall LC rates were $95.2 \%$ (12 months) and $70.5 \%$ (18 months). The primary tumor was controlled (CR or PR) 3 months following the initial therapy in 19 of 23 patients. During the last evaluation, 17 of 23 patients were considered to have maintained local control. The remaining four patients had recurrences within the radiation field.

Two patients developed progression of their primary tumors and both had bleeding from the tumor and required blood transfusion. One patient had pelvic lymph node metastasis and the other a recurrence in the pelvic wall. One patient who was evaluated as having achieved CR 3 months after RT alone had a recurrence of her primary tumor 15 months following therapy. Another patient who was evaluated as having achieved PR 3 months after RT alone had a recurrence of her primary tumor 27 months following therapy. Neither of these patients had concurrent chemotherapy nor HDR-ICBT. The EQD2 to 
Table I. Patient and treatment-related characteristics.

\begin{tabular}{|c|c|}
\hline Total number of patients & 23 \\
\hline \multicolumn{2}{|l|}{ Age, years } \\
\hline Median & $52($ range $=39-78)$ \\
\hline \multicolumn{2}{|l|}{ ECOG PS } \\
\hline 0 & 10 \\
\hline 1 & 12 \\
\hline 2 & 1 \\
\hline \multicolumn{2}{|l|}{ Histology } \\
\hline Squamous cell carcinoma & 13 \\
\hline Adeno-squamous carcinoma & 2 \\
\hline Adenocarcinoma & 3 \\
\hline Poorly differentiated carcinoma & 4 \\
\hline Neuroendocrine carcinoma & 1 \\
\hline \multicolumn{2}{|l|}{ Maximum primary tumor diameter (mm) } \\
\hline Median & $60($ range $=40-150)$ \\
\hline \multicolumn{2}{|l|}{$\mathrm{T}$ category } \\
\hline $\mathrm{T} 2 \mathrm{a}$ & 1 \\
\hline $\mathrm{T} 2 \mathrm{~b}$ & 4 \\
\hline T3a & 2 \\
\hline $\mathrm{T} 3 \mathrm{~b}$ & 9 \\
\hline $\mathrm{T} 4$ & 7 \\
\hline \multicolumn{2}{|l|}{$\mathrm{N}$ category } \\
\hline No & 3 \\
\hline N1 & 20 \\
\hline \multicolumn{2}{|l|}{ Number of lung metastases } \\
\hline the & 2 \\
\hline 2 & 3 \\
\hline 3 & 1 \\
\hline 4 & 1 \\
\hline$\geq 5$ & 16 \\
\hline \multicolumn{2}{|l|}{ Maximum diameter of lung metastases (mm) } \\
\hline$<10 \mathrm{~mm}$ & 7 \\
\hline$\geq 10 \mathrm{~mm}$ & 16 \\
\hline \multicolumn{2}{|l|}{ Lung metastatic site } \\
\hline Right & 6 \\
\hline Left & 2 \\
\hline Bilateral & 15 \\
\hline \multicolumn{2}{|l|}{ Site of distant metastatic site except lung* } \\
\hline None & 10 \\
\hline Para-aortic lymph node* & 9 \\
\hline Multiple lymph node metastases except para-aorta* & 12 \\
\hline Liver & 4 \\
\hline Peritoneum & 3 \\
\hline Bone & 6 \\
\hline Ovary & 1 \\
\hline Subcutaneous metastasis & 1 \\
\hline \multicolumn{2}{|l|}{ Number of distant metastatic organs except lung } \\
\hline 0 & 10 \\
\hline $1-3$ & 7 \\
\hline$\geq 4$ & 6 \\
\hline \multicolumn{2}{|l|}{ Hydronephrosis } \\
\hline Yes (bilateral) & $9(6)$ \\
\hline No & 14 \\
\hline \multicolumn{2}{|l|}{ Pretreatment hemoglobin $(\mathrm{g} / \mathrm{dl})$} \\
\hline Median & $9.6($ range $=6.5-12.7$ \\
\hline \multicolumn{2}{|l|}{ Chemotherapy at RT } \\
\hline RT alone & 7 \\
\hline Concurrent CRT & 16 \\
\hline Chemotherapy before RT & 2 \\
\hline \multicolumn{2}{|l|}{ After RT treatment (overlap/duplicate) } \\
\hline Chemotherapy & 17 \\
\hline Surgery & 2 \\
\hline RT (another site) & 5 \\
\hline
\end{tabular}

*Some patients had overlapping sites. T category, $\mathrm{N}$ category: TNM Classification of Malignant Tumors, 8th edition (11). PS: Performance status; ECOG: Eastern Cooperative Oncology Group; CRT: chemoradiotherapy; RT: radiation therapy.

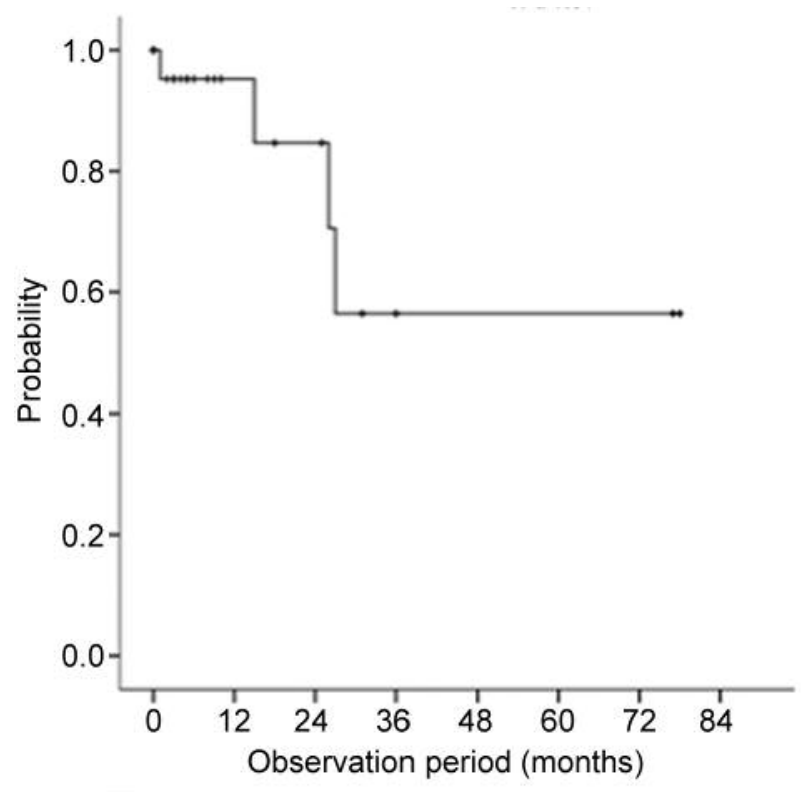

Figure 1. Kaplan-Meier curves for local control rate.

the primary tumor was $50.0 \mathrm{~Gy}$ and $49.6 \mathrm{~Gy}$ in the two patients who developed recurrences of their primary tumors.

Survival. Figure 2A shows Kaplan-Meier curves for the overall survival rate, which was $47.2 \%$ (12-months) and $22.8 \%$ (24-months).

Five of 23 patients were alive during the last follow-up, 4 of them with a complete response (CR), and thus, diseasefree. The median survival time of these 5 patients was 36 (range $=31-78$ ) months. Three of these 4 patients had lung metastases only and 3 had squamous cell carcinoma (SCC). The remaining patient had poorly differentiated carcinoma and both lung metastases and mediastinal lymph node metastases. The $\mathrm{T}$ stages (11) of these patients were T2b or T3b, while a single patient was N0. Two patients underwent surgery for lung metastases; one of them developed brain metastasis following surgery that was controlled by RT. The other patient received chemotherapy for lung metastases.

Concerning the causes of death, one patient developed recurrence of her primary tumor, 13 had multiple metastases, including liver, bone, and peritoneum, and two patients died of bleeding from metastases (duodenum or lung). In only one of these patients was the cause of death related to lung metastases. Two patients changed hospitals soon after RT and no further information was available.

There was a significant difference in OS between patients with lung metastases only and those with lung metastases and metastases to other sites, including lymph nodes or other organ metastases $(p=0.017)$ (Figure 2B) There was a significant difference in OS between the group of lung metastasis without 
other organ metastasis and the group of lung metastasis with other organ metastases $(p=0.001)$ (Figure $2 \mathrm{C}$ ).

Prognostic factors. The prognostic factors identified are shown in Table II. The LC was significantly better in patients with the following characteristics: i) $\mathrm{PS}=0 \quad(p=0.043)$, concurrent chemoradiotherapy (CCRT) $(p=0.01)$, and ii) non-bilateral hydronephrosis $(p=0.025)$. None of the following factors significantly affected the LC: i) diameter of primary tumor $\geq 100 \mathrm{~mm}(p=0.68)$, ii) $\mathrm{T}$ stage $<\mathrm{T} 3 \mathrm{~b}$ $(p=0.326)$, iii) positive pelvic lymph nodes $(p=0.78)$, iv $)$ lung metastases $\geq$ four ( $p=0.83), \mathrm{v})$ EQD2 $\geq 62$ Gy $(p=0.94)$, and vi) diameter of lung metastases $<10 \mathrm{~mm}(p=0.65)$. The OS was significantly better in patients with the following factors: i) $\mathrm{PS}=0 \quad(p=0.015)$, ii $)$ tumor size $<100 \mathrm{~mm}$ $(p<0.01)$, iii) $\mathrm{T}$ stage $<\mathrm{T} 3 \mathrm{~b}(p=0.029)$, iv $)$ ipsilateral lung metastases $(p=0.039)$, and $v)$ number of lung metastasis $<$ four $(p=0.035)$. Neither of the following factors significantly affected OS: i) CCRT ( $p=0.07)$ and ii) diameter of lung metastases $(p=0.14)$.

The effect of concurrent chemotherapy was not statistically significant $(p=0.07)$. However, the lung metastases did not progress in 6 of 16 patients who received concurrent chemotherapy, five of whom had bilateral multiple lung metastases. The lung metastases resolved completely in 3 of these patients and reduced in size in the remaining three patients. In particular, two patients achieved CR and had long survivals. In contrast, the lung metastases of all 8 patients who did not receive chemotherapy progressed.

Treatment tolerance. Table III shows treatment-related acute and late toxicities. Acute toxicities were tolerable/ manageable, and no patient had $\geq$ Grade 2 non-hematologic toxicities, including genitourinary (GU), gastrointestinal (GI) toxicity and dermatitis. Eighteen patients (78.3\%) developed $\geq$ Grade 3 acute hematology toxicity (HT) including at least one of the following: i) anemia, ii) low total white blood cell, iii) neutrophil and/or iv) platelet count. In particular, 11 patients developed $\geq$ Grade 3 anemia. Total white blood cell or neutrophil counts decreased $\geq$ Grade 3 in 10 patients, nine of whom were receiving chemotherapy. All patients recovered from HT following treatment.

Interestingly, no patient had treatment-related $\geq$ Grade 2 late toxicity. Grade 1 GI toxicity occurred in 8 patients and GU toxicity in 4 , however, all these symptoms were shortlived.

\section{Discussion}

Distant metastases are present at the time of diagnosis in $2.9 \%-14 \%$ of patients with cervical cancer $(2,3)$. For many years, treatment outcomes in these patients have been poor, excluding those with para-aortic lymph-node metastases
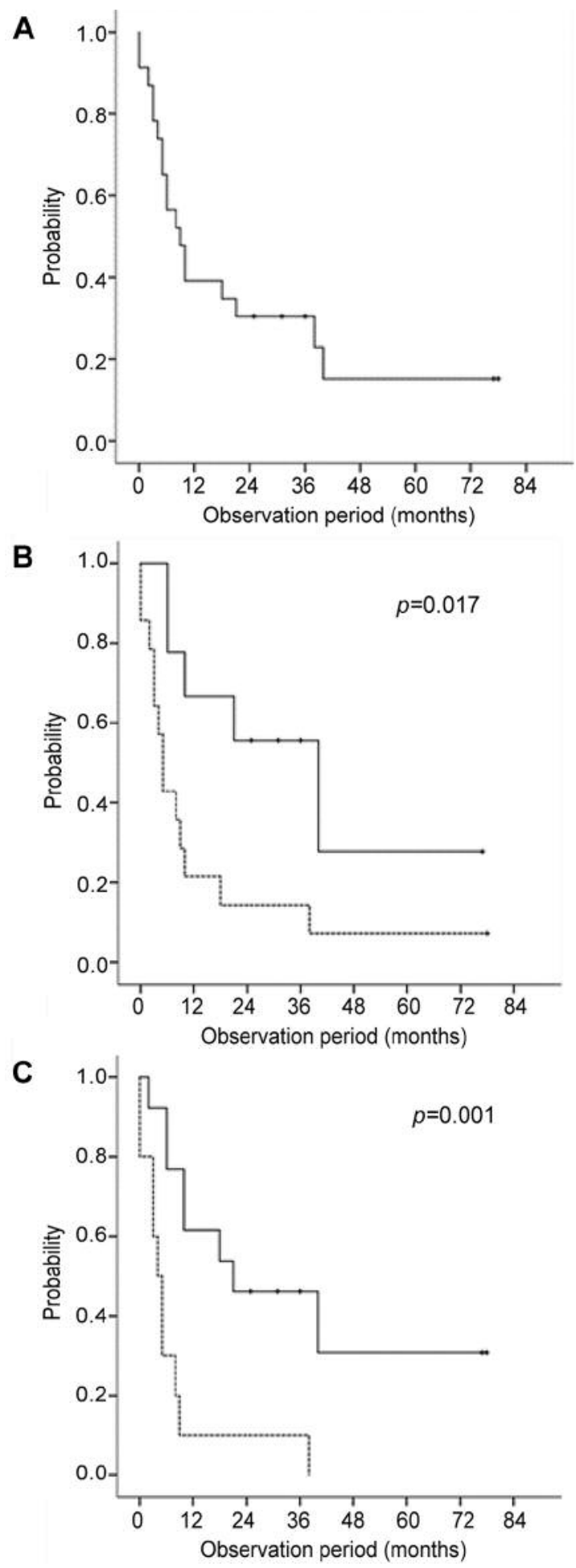

Figure 2. Kaplan-Meier curves for overall survival. (A) Kaplan-Meier curves for the overall survival rate. (B) Overall survival rate comparison between the group of lung metastasis only (solid line) and the group of lung metastasis with other sites, including lymph nodes or other organ metastases (dot line). (C) Overall survival rate comparison between the group of lung metastasis without other organ metastasis (solid line) and the group of lung metastases with other organ metastasis (dot line). 
Table II. Prognostic factors.

\begin{tabular}{|c|c|c|c|c|c|}
\hline Prognostic factor & $\begin{array}{l}\text { No. of } \\
\text { patients }\end{array}$ & $\begin{array}{l}\text { 1-year primary } \\
\text { tumor control }(\%)\end{array}$ & $p$-Value & $\begin{array}{l}1 \text {-year overall } \\
\text { survival }(\%)\end{array}$ & $p$-Value \\
\hline \multicolumn{6}{|l|}{ Age, years } \\
\hline$<50$ & 9 & 77.8 & \multirow[t]{2}{*}{0.266} & 85.7 & \multirow[t]{2}{*}{0.443} \\
\hline$\geq 50$ & 14 & 50.0 & & 100 & \\
\hline \multicolumn{6}{|l|}{ ECOG PS } \\
\hline 0 & 10 & 100.0 & \multirow[t]{2}{*}{0.043} & 60.0 & \multirow[t]{2}{*}{0.015} \\
\hline $1-2$ & 13 & 90.0 & & 23.1 & \\
\hline \multicolumn{6}{|l|}{ Histology } \\
\hline SCC & 13 & 100.0 & \multirow[t]{2}{*}{0.332} & 50.0 & \multirow[t]{2}{*}{0.402} \\
\hline Others & 10 & 87.5 & & 22.2 & \\
\hline \multicolumn{6}{|c|}{ Maximum primary tumor diameter $(\mathrm{mm})$} \\
\hline$<100$ & 18 & 94.4 & \multirow[t]{2}{*}{0.683} & 50.0 & \multirow[t]{2}{*}{$<0.010$} \\
\hline$\geq 100$ & 5 & 0 & & 0 & \\
\hline \multicolumn{6}{|l|}{$\mathrm{T}$ category } \\
\hline$<\mathrm{T} 3 \mathrm{~b}$ & 16 & 100.0 & \multirow{2}{*}{0.326} & 80.0 & \multirow[t]{2}{*}{0.029} \\
\hline$\geq \mathrm{T} 3 \mathrm{~b}$ & 7 & 85.7 & & 27.8 & \\
\hline \multicolumn{6}{|l|}{$\mathrm{N}$ category } \\
\hline No & 3 & 100.0 & \multirow[t]{2}{*}{0.780} & 66.7 & \multirow[t]{2}{*}{0.737} \\
\hline N1 & 20 & 94.4 & & 35.0 & \\
\hline \multicolumn{6}{|c|}{ No. of lung metastases } \\
\hline$<4$ & 6 & 100.0 & \multirow[t]{2}{*}{0.829} & 71.4 & \multirow[t]{2}{*}{0.035} \\
\hline$\geq 4$ & 17 & 92.9 & & 25.0 & \\
\hline \multicolumn{6}{|c|}{ Diameter of lung metastases (mm) } \\
\hline$<10 \mathrm{~mm}$ & 7 & 100.0 & \multirow[t]{2}{*}{0.646} & 63.6 & \multirow[t]{2}{*}{0.136} \\
\hline$\geq 10 \mathrm{~mm}$ & 16 & 90.0 & & 16.7 & \\
\hline \multicolumn{6}{|c|}{ Lung metastatic site } \\
\hline unilateral & 8 & 100.0 & \multirow[t]{2}{*}{0.790} & 71.4 & 0.039 \\
\hline bilateral & 15 & 92.7 & & 25.0 & \\
\hline Hydronephrosis & & & & & \\
\hline No/unilateral & 17 & 100.0 & 0.025 & 41.2 & 0.574 \\
\hline bilateral & 6 & 83.3 & & 33.3 & \\
\hline Pretreatment hemo & & & & & \\
\hline$<7$ & 4 & 100.0 & 0.900 & 31.6 & 0.195 \\
\hline$\geq 7$ & 19 & 75.0 & & 75.0 & \\
\hline Concurrent CRT & & & & & \\
\hline Yes & 16 & 100.0 & 0.010 & 46.7 & 0.070 \\
\hline No & 7 & 83.3 & & 25.0 & \\
\hline EQD2 & & & & & \\
\hline$<62$ & 10 & 100.0 & 0.940 & 40.0 & 0.707 \\
\hline$\geq 62$ & 13 & 92.3 & & 38.4 & \\
\hline
\end{tabular}

PS: Performance status; ECOG: Eastern Cooperative Oncology Group; SCC: squamous cell carcinoma; CRT: chemoradiotherapy; EQD2: equivalent dose in 2 Gy fractions.

only. The 5-year survival rate of patients with Stage IVB UCC at diagnosis is reportedly only $9 \%-16.5 \%(4,14,15)$. Stage IVB disease is categorized as hematogenous or lymphatic metastases. Concerning lymphatic metastasis, Matthew et al., (7) have reported a 3-year-OS of $63.7 \%$ in patients with supraclavicular lymph node metastases from UCC, including metachronous and synchronous metastases. Whereas hematogenous metastases commonly involve the lung, liver, bone, brain and so on, the lung is the most common site of both metachronous and synchronous single organ metastases $(3,16,17)$.
Treatment of metachronous lung metastases using surgery, stereotactic body radiotherapy (SBRT), or chemotherapy, may improve the outcomes; however, reported series have included few patients with synchronous lung metastases (1823). Patients with pulmonary metastases at initial diagnosis of cervical cancer (hematogenous metastasis) are considered to have a systematic disease requiring systematic chemotherapy with various regimens (3, 20-22, 24-27).

Patients with Stage IVB UCC and organ metastases have traditionally been treated with a palliative intent (2); however, new radiation technology and chemotherapy 
regimens have recently emerged, and the treatment options are now expanding, and include aggressive treatment (surgery or chemotherapy) for Stage $\operatorname{IVB} \operatorname{UCC}(4,27,28)$.

To the best of our knowledge, no reported studies have previously analyzed prognostic factors in patients with UCC with lung metastases at initial diagnosis.

In the present study, 17 (73.9\%) of 23 patients achieved local control within the radiation field at the last evaluation. Only 4 patients developed recurrence within the radiation field. One of these 4 died of recurrence of her primary tumor. In the two patients who developed recurrence of their primary tumors, the EQD2 to the primary tumor was 50.0 Gy and 49.6 Gy, which is lower than the median EQD2 to primary tumors of $62.1 \mathrm{~Gy}$. These two patients bled from their recurrent tumors. Thus, even if a patient has distant metastases, she may benefit from controlling the growth of the primary tumor and prevention of serious symptoms, such as bleeding. The remaining two patients could not continue chemotherapy because the recurrence of their tumor within the pelvic/radiation field led to hydronephrosis, preventing administration of further chemotherapy. They subsequently developed multiple organ metastases and died.

Previous studies have documented that chemotherapy contributes to improving the prognosis of patients with distant metastases (4). Prevention of complications from recurrence or progression of tumor in the pelvis, such as hydronephrosis, may enable the continuation of chemotherapy. Thus, the control of recurrence/progression in the pelvis may be worthwhile.

Several studies have reported that patients with oligometastases or oligo-recurrence from lung or breast cancer are good candidates for curative radiation therapy ( 7 , $29,30)$. There have been some reports on metachronous lung (oligo-) metastases from gynecologic malignancies. The 5year-OS of patients with pulmonary metastases from UCC is reportedly $0-60 \%(18-21,31,32)$ and the event-free period is 12 months following surgery or chemotherapy (10). The median progression-free survival in gynecological malignancies who receive stereotactic radiotherapy is reportedly 10.8 months in patients with oligometastatic disease, including lung, liver, and lymph nodes (33).

Our results are poorer than those reported for metachronous lung metastases elsewhere. One possible reason is that the control of the primary tumor has usually been achieved in patients with metachronous lung metastases and most of them only had lung metastasis. Additionally, those patients were in good condition/PS to tolerate surgery or other aggressive treatment modalities. In contrast, all patients in our study had Stage IVB disease with synchronous metastases and their primary tumors were not controlled at diagnosis. Additionally, 22 of 23 patients had bleeding and 5 of them required blood transfusion. In other words, at the time of initial treatment, the primary tumor was life-threatening and the treatment priority was to control it.
Table III. Acute and late toxicity.

\begin{tabular}{|c|c|c|c|c|c|}
\hline \multirow[t]{2}{*}{ Acute toxicity } & \multicolumn{5}{|c|}{ Grade (n) } \\
\hline & 1 & 2 & 3 & 4 & 5 \\
\hline \multicolumn{6}{|l|}{$\begin{array}{l}\text { HT Hematology toxicity/ } \\
\text { Blood/bone marrow }\end{array}$} \\
\hline Anemia & 3 & 8 & 11 & 0 & 0 \\
\hline Neutropenia & 1 & 3 & 8 & & - \\
\hline Thrombocytopenia & 3 & 1 & 1 & - & - \\
\hline \multicolumn{6}{|l|}{ General conditions } \\
\hline Weight loss & 0 & 0 & 0 & - & - \\
\hline Edema & 2 & 0 & 0 & - & - \\
\hline Dermatitis and mucositis & 16 & 0 & 0 & 0 & 0 \\
\hline \multicolumn{6}{|l|}{ Gastrointestinal } \\
\hline Anorexia & 5 & 0 & 0 & 0 & 0 \\
\hline Diarrhea & 15 & 0 & 0 & - & - \\
\hline Nausea & 14 & 0 & - & - & - \\
\hline Rectal hemorrhage & 2 & 0 & 0 & 0 & 0 \\
\hline \multicolumn{6}{|l|}{ Genitourinary } \\
\hline Urinary frequency & 8 & 0 & - & - & - \\
\hline Cystitis, non-infective & 1 & 0 & 0 & 0 & 0 \\
\hline \multirow[t]{2}{*}{ Late toxicity } & \multicolumn{5}{|c|}{ Grade (n) } \\
\hline & 1 & 2 & 3 & 4 & 5 \\
\hline \multicolumn{6}{|l|}{ Gastrointestinal } \\
\hline Anorexia & 1 & 0 & 0 & 0 & 0 \\
\hline Diarrhea & 2 & 0 & 0 & - & - \\
\hline Nausea & 2 & 0 & - & - & - \\
\hline Rectal hemorrhage & 3 & 0 & 0 & 0 & 0 \\
\hline \multicolumn{6}{|l|}{ Genitourinary } \\
\hline Urinary frequency & 2 & 0 & - & - & - \\
\hline Cystitis, non-infective & 2 & 0 & 0 & 0 & 0 \\
\hline
\end{tabular}

Because most patients had no symptoms of lung metastases, treatment of those metastases was deferred.

In the present study, 5 people were alive at the last evaluation and 4 of them were in CR. The median survival time of these patients was 36 (range $=31-78$ ) months. Thus, some patients with UCC and lung metastases have a good long-term prognosis. In our study, the favorable prognostic factors identified were: i) lung metastases without metastases to any other organ (only lung metastases with or without lymph node metastases), ii) ipsilateral lung metastases, and iii) number of lung metastasis $\leq 4$. The prognostic factors of few metastases and limited location of metastases is equivalent to oligometastases in the lung. We recommend that such patients receive treatment with curative intent.

Additionally, in the present study, administration of concurrent chemotherapy was not associated with a 
significant prognostic advantage. However, as mentioned in our results chapter, the lung metastases were controlled in 6 of 16 patients who received concurrent chemotherapy, whereas the lung metastases progressed in all patients who did not receive concurrent chemotherapy. A significant advantage may be found in a larger series. We recommend concurrent chemoradiotherapy, provided that the patients can tolerate it. Furthermore, when hematogenous metastases develop in other organs, the prognosis is poorer.

In our study, patients with only lung metastases had a better prognosis compared to those with other metachronous hematogenous metastases/organ metastases, such as brain or bone metastases. Hwang et al., have reported a median survival time following diagnosis of brain metastases of only 5.9 months (32), while median survival times following detection of metachronous bone metastases range from 5.5 to under 12 months $(34,35)$.

In the present study, the only acute toxicity $\geq$ Grade 3 was of hematological nature, which is similar to that has previously been reported for CCRT in patients with UCC without distant metastasis. There was no late toxicity $\geq$ Grade 2 . The low rate of late toxicity may be attributed to the fact that few patients had long survivals.

In our study, only two patients underwent surgery and not all patients had PET-CT. Additionally, there was no definitive evidence that they did not have primary lung cancer. However, given that 18 of the patients $(78.3 \%)$ had advanced primary cervical cancer $(\geq \mathrm{T} 3 \mathrm{~b})$, it was reasonable to conclude that lung metastases were considerably more likely than primary lung cancer.

Since 2018, the combination chemotherapy (bevacizumab, paclitaxel and topotecan) is delivered to UCC patients. This study reports the treatment results before this regimen started. Many more treatment options, including this regimen, will improve outcomes of these patients in the near future.

Limitations of our study include the small number of patients, the short observation periods, its retrospective nature, and that some of the apparent lung metastases might have been primary lung cancer. Proactive aggressive RT is safe and effective in patients Stage IVB UCC with lung metastases. Prognostic factors in these patients comprise: i) lung metastases without any metastases in other organs, ii) ipsilateral lung metastases, and iii) number of lung metastasis $\leq 4$. These factors together denote oligometastases in the lung. Further studies are needed to improve treatment outcomes for these patients. Meanwhile, we consider that patients with oligometastases in the lung may be good candidates for aggressive radiation therapy with a curative intent.

\section{Conflicts of Interest}

None of the Authors have any conflicts of interest associated with this study.

\section{Authors' Contributions}

YM analyzed the patient data and contributed to writing the manuscript. All Authors read and approved the final manuscript.

\section{References}

1 Cervical Cancer, Estimated Incidence, Mortality and Prevalence Worldwide in 2012. Available at: https://www.uicc.org/ sites/main/files/private/GLOBOCAN2012_Cancer_FactSheets_C ervicalCancer.pdf (Accessed in February 25th, 2019)

2 Zighelboim I, Taylor NP, Powell MA, Gibb RK, Rader JS, Mutch DG and Grigsby PW: Outcomes in 24 selected patients with stage IVB cervical cancer and excellent performance status treated with radiotherapy and chemotherapy. Radiat Med 24(9): 625-630, 2006. PMID: 17111271. DOI: 10.1007/s11604-006-0082-6

3 Anderson TM, McMahon JJ, Nwogu CE, Pombo MW, Urschel JD, Driscoll DL and Lele SB: Pulmonary resection in metastatic uterine and cervical malignancies. Gynecol Oncol 83(3): 472476, 2001. PMID: 11733957. DOI: 10.1006/gyno.2001.6427

4 Hata M, Koike I, Miyagi E, Asai-Sato M, Kaizu H, Mukai Y, Takano S, Ito E, Sugiura M and Inoue T: Radiation therapy for patients with bone metastasis from uterine cervical cancer: Its role and optimal radiation regimen for palliative care. Anticancer Res 38(2): 1033-1040, 2018. PMID: 29374737. DOI: 10.21873/ anticanres.12319

5 Niibe Y, Kenjo M, Kazumoto T, Michimoto K, Takayama M, Yamauchi C, Kataoka M, Suzuki K, Ii N, Uno T, Takanaka T, Higuchi K, Yamazaki H, Tokumaru S, Oguchi M and Hayakawa K: Japanese Isolated Para-Aortic Lymph Node Recurrence of Uterine Cervical Carcinoma Study Group. Multi-institutional study of radiation therapy for isolated para-aortic lymph node recurrence in uterine cervical carcinoma: 84 subjects of a population of more than 5,000. Int J Radiat Oncol Biol Phys 66(5): 1366-1369, 2006. PMID: 17126206. DOI: 10.1016/ j.ijrobp.2006.07.1384

6 Hata M, Omura M, Miyagi E, Koike I, Numazaki R, Asai-Sato M, Tayama Y, Ogino I, Hirahara F and Inoue T: The role of radiation therapy for uterine cervical cancer with distant metastasis. Oncology 83(2): 67-74, 2012. PMID: 22760158. DOI: $10.1159 / 000337985$

7 Ning MS, Ahobila V, Jhingran A, Stecklein SR, Frumovitz M, Schmeler KM, Eifel PJ and Klopp AH: Outcomes and patterns of relapse after definitive radiation therapy for oligometastatic cervical cancer. Gynecol Oncol 148(1): 132-138. 2018 PMID: 29089122. DOI: 10.1016/j.ygyno.2017.10.017

$8 \mathrm{Li} \mathrm{H}, \mathrm{Wu} \mathrm{X}$ and Cheng X: Advances in diagnosis and treatment of metastatic cervical cancer. J Gynecol Oncol 27(4): e43, 2016. PMID: 27171673. DOI: 10.3802/jgo.2016.27.e43

9 Ballon SC, Berman ML, Donaldson RC, Growdon WA and Lagasse LD: Pulmonary metastases of endometrial carcinoma. Gynecol Oncol 7(1): 56-65,1979. PMID: 437561.

$10 \mathrm{Ki}$ EY, Lee KH, Park JS and Hur SY: A clinicopathological review of pulmonary metastasis from uterine cervical cancer. Cancer Res Treat 48(1): 266-272, 2016. PMID: 25715766. DOI: 10.4143/crt.2014.206

11 Brierley JD, Gospodarowicz MK and Wittekind C (eds.): TNM Classification of Malignant Tumours, 8th edition, 2017. Ohn Wiley \& Sons, LTD. 
12 Response Evaluation Criteria in Solid Tumor (RECIST) 1.1 Available at: https://recist.eortc.org/recist-1-1-2/(Accessed in February 25th, 2019)

13 Common Terminology Criteria for Adverse Events v4.0 (CTCAE). Available at: https://ctep.cancer.gov/protocol Development/ electronic_applications/ctc.htm\#ctc_40 (Accessed in February 25th, 2019)

14 Quinn MA, Benedet JL, Odicino F, Maisonneuve P, Beller U, Creasman WT, Heintz AP, Ngan HY and Pecorelli S: Carcinoma of the cervix uteri. FIGO 26th annual report on the results of treatment in gynecological cancer. Int J Gynaecol Obstet 95: S43-S103, 2006. PMID: 17161167. DOI: 10.1016/S00207292(06)60030-1

15 Ishikawa M, Nakayama K, Rahman MT, Rahman M, Katagiri A, Katagiri H, Ishibashi T, Iida $\mathrm{K}$ and Miyazaki K: A case of stage $\mathrm{IVb}$ cervical carcinoma in which survival was prolonged by two different chemotherapies and CCRT. Gan To Kagaku Ryoho 39: 451-455, 2012. PMID: 22421778.

16 Gallousis S: Isolated lung metastases from pelvic malignancies. Gynecol Oncol 7(2): 206-214, 1979. PMID: 437571.

17 Carlson V, Delclos L and Fletcher GH: Distant metastases in squamous-cell carcinoma of the uterine cervix. Radiology $88(5)$ : 961-966, 1967. PMID: 6025051. DOI: 10.1148/88.5.961

18 Lim MC, Lee HS, Seo SS, Kim MS, Kim JY, Zo JI and Park SY: Pathologic diagnosis and resection of suspicious thoracic metastases in patients with cervical cancer through thoracotomy or video-assisted thoracic surgery. Gynecol Oncol 116(3): 478482, 2010. PMID: 19889448. DOI: 10.1016/j.ygyno.2009.10.039

19 Seki M, Nakagawa K, Tsuchiya S, Matsubara T, Kinoshita I, Weng SY and Tsuchiya E: Surgical treatment of pulmonary metastases from uterine cervical cancer. Operation method by lung tumor size. J Thorac Cardiovasc Surg 104(4): 876-881, 1992. PMID: 1405684

20 González Casaurrán G, Simón Adiego C, Peñalver Pascual R, Moreno Mata N, Lozano Barriuso MÁ and González Aragoneses F: Surgery of female genital tract tumour lung metastases. Arch Bronconeumol 47(3): 134-137, 2011. PMID: 21392876. DOI: 10.1016/j.arbres.2010.10.013

21 Clavero JM, Deschamps C, Cassivi SD, Allen MS, Nichols FC 3rd, Barrette BA, Larson DR and Pairolero PC: Gynecologic cancers: factors affecting survival after pulmonary metastasectomy. Ann Thorac Surg 81(6): 2004-2007, 2006. PMID: 16731120. DOI: 10.1016/j.athoracsur.2006.01.068

22 Park HJ, Chang AR, Seo Y, Cho CK, Jang WI, Kim MS and Choi C: Stereotactic body radiotherapy for recurrent or oligometastatic uterine cervix cancer: A cooperative study of the Korean Radiation Oncology Group (KROG 14-11). Anticancer Res 35(9): 5103-5110, 2015. PMID: 26254414.

23 Panek G, Gawrychowski K, Sobiczewski P, Derlatka P, DanskaBidzinska A, Gmyrek L and Bidzinski M: Results of chemotherapy for pulmonary metastases of carcinoma of the cervix in patients after primary surgical and radiotherapeutic management. Int J Gynecol Cancer 17(5): 1056-1061, 2007. PMID: 17466044. DOI: 10.1111/j.1525-1438.2007.00879.x

24 Long HJ 3rd: Management of metastatic cervical cancer: review of the literature. J Clin Oncol 25(20): 2966-2974, 2007. PMID: 17617528. DOI: 10.1200/JCO.2006.09.3781
25 Goto S, Sakai S, Kera J, Suma Y, Soma GI and Takeuchi S: A case report of recurrent cervical cancer which responded to a combination of biological therapies. Eur J Gynaecol Oncol 15(3): 235-240, 1994. PMID: 7957329.

$26 \mathrm{NCCN}$ clinical practice guidelines in oncology. Cervical cancer. Version 1. 2017. Available at: https://www2.tri-kobe.org/nccn/ guideline/gynecological/english/cervical.pdf (Accessed in February 25th, 2019)

27 Oishi S, Kudaka W, Toita T, Ariga T, Nakamoto T, Wakayama A, Nagai Y, Kaneshima I, Nishihira K and Aoki Y: Prognostic factors and treatment outcome for patients with stage IVB cervical cancer. Anticancer Res 36(7): 3471-3475, 2016. PMID: 27354610.

28 Huang K, Jia M, Li P, Han J, Zhang R, Li Q, Qiao Y, Xu T, Ruan P, Song Q, Li Y and Fu Z: Radiotherapy improves the survival of patients with metastatic cervical cancer: A propensity-matched analysis of SEER database. Int J Gynecol Cancer 28(7): 1360-1368, 2008. PMID: 30036221. DOI: 10.1097/IGC.0000000000001313

29 Niibe Y, Kuranami M, Matsunaga K, Takaya M, Kakita S, Hara T, Sekiguchi K, Watanabe M and Hayakawa K: Value of highdose radiation therapy for isolated osseous metastasis in breast cancer in terms of oligo-recurrence. Anticancer Res 28(6B): 3929-3931, 2008. PMID: 19192651.

30 Gomez DR, Niibe Y and Chang JY: Oligometastatic disease at presentation or recurrence for nonsmall cell lung cancer. Pulm Med 2012: 396592, 2012. PMID: 22900169. DOI: 10.1155/ 2012/396592

31 Mountain CF, McMurtrey MJ and Hermes KE: Surgery for pulmonary metastasis: a 20-year experience. Ann Thorac Surg 38: 323-330, 1984. PMID: 6486949. DOI: 10.1016/s00034975(10)62280-1

32 Hwang JH, Yoo HJ, Lim MC, Seo SS, Kang S, Kim JY and Park SY: Brain metastasis in patients with uterine cervical cancer. J Obstet Gynaecol Res 39(1): 287-291, 2013. PMID: 22690955. DOI: $10.1111 / \mathrm{j} .1447-0756.2012 .01927 . x$

33 Mesko S, Sandler K, Cohen J, Konecny G, Steinberg M and Kamrava M: Clinical outcomes for stereotactic ablative radiotherapy in oligometastatic and oligoprogressive gynecological malignancies. Int J Gynecol Cancer 27(2): 403-408, 2017. PMID: 27870704. DOI: 10.1097/IGC.00000000 00000869

34 Matsumiya H, Todo Y, Okamoto K, Takeshita S, Yamazaki H, Yamashiro $\mathrm{K}$ and Kato $\mathrm{H}$ : A prediction model of survival for patients with bone metastasis from uterine cervical cancer. $\mathrm{J}$ Gynecol Oncol 27(6): e55, 2016. PMID: 27550401.

35 Kanayama T, Mabuchi S, Shimura K, Hisamatsu T, Isohashi F, Hamasaki $\mathrm{T}$ and Kimura $\mathrm{T}$ : Prognostic factors for survival in cervical cancer patients with bone metastasis. Eur J Gynaecol Oncol 36(3): 290-293, 2015. PMID: 26189255. 